\title{
The effect of cryogenic temperature and change in deformation mode on the limiting grain size in a severely deformed dilute aluminium alloy
}

\author{
Y. Huang, P.B. Prangnell* \\ Manchester Materials Science Centre, The University of Manchester, Grosvenor Street, Manchester M17HS, UK
}

Received 1 November 2007; received in revised form 5 December 2007; accepted 5 December 2007

Available online 5 February 2008

\begin{abstract}
With the aim of investigating the factors that limit the production of true nanograined materials by cryogenic severe deformation, the grain structures formed in an $\mathrm{Al}-0.1 \% \mathrm{Mg}$ alloy have been studied in plane strain compression at temperatures down to $77 \mathrm{~K}$, following prior severe plastic deformation (SPD) by equal channel angular extrusion. Changing the deformation mode alone had little effect on increasing the rate of grain refinement. At the minimum cryogenic temperature $(77 \mathrm{~K})$ the samples still contained $\sim 30 \%$ low angle boundaries and a nanoscale high-angle boundary (HAB) spacing was only obtained in one dimension. At high strains a steady-state minimum HAB spacing was approached, irrespective of the temperature, where the rate of grain refinement stagnated. It is shown that the minimum grain size achievable in SPD is limited by a balance between the rate of compression of the HAB spacing and dynamic grain coarsening. At low temperatures this is controlled by abnormally high boundary migration rates, which are difficult to explain with existing theories of grain boundary mobility.
\end{abstract}

(c) 2007 Acta Materialia Inc. Published by Elsevier Ltd. All rights reserved.

Keywords: Severe plastic deformation (SPD); Nanocrystalline; Dynamic grain coarsening; Cryogenic temperature; EBSD

\section{Introduction}

To date, severe deformation processing (SDP) has been successfully used to produce submicron grain structures, and in some cases nanoscale crystallite sizes, in a wide range of alloys (e.g. [1-12]). However, an important limitation of SDP is that the rate of grain refinement becomes increasingly inefficient with higher levels of strain [10-12]. Even in conventional high strain rolling, the rate of reduction in high-angle boundary (HAB) spacing reduces to a very low rate by stage IV hardening [13], and at the far greater strains reached by SPD techniques a steady-state grain structure is approached $[1,10-12]$. For example, during equal channel angular extrusion (ECAE) of aluminium alloys, grain refinement reaches a limit when the $\mathrm{HAB}$ spacing converges with the subgrain size, and the fraction

\footnotetext{
* Corresponding author. Tel.: +44 161306 3610; fax: +44 1613063586 E-mail address: philip.prangnell@manchester.ac.uk (P.B. Prangnell).
}

of $\mathrm{HAB}$ area typically saturates at $\sim 70-80 \%[3,4,12,14]$. In deformation by ECAE at room temperature using route A, Prangnell et al. [12] have reported that there is little further reduction in the transverse $\mathrm{HAB}$ spacing with strain in the range $\varepsilon_{\mathrm{vm}}=8-17$. However, a true steady-state was not achieved and there was still a noticeable reduction in grain length, due to the break-up of the final remaining long, fibrous, ribbon grain fragments. Nevertheless, in general only small changes in grain size have been seen to take place in SPD when the applied strain is increased above $10[1,10,12]$. Steady-state grain sizes have also been reported in other ultra-high strain deformation processes, like cryogenic ball-milling $[15,16]$. There is thus a minimum grain size achievable in a material by a given SPD process under constant deformation conditions.

In view of the fact that the rate of grain refinement becomes increasingly inefficient with strain, changing the deformation mode may help to reinvigorate the generation of new HAB area. For example, a change in deformation mode can alter the texture development and increase the 
rate of compression of the $\mathrm{HAB}$ spacing geometrically required by the imposed strain [17].

It is well documented that a steady-state subgrain size is observed in warm deformation of metals due to dynamic recovery (e.g. [18]). In severely deformed alloys a constant grain size at ultra-high strains has similarly been attributed to dynamic recovery $[10-12,19]$. However, as pointed out by Humphreys et al. [11], the restoration processes are currently poorly understood, particularly at low temperatures, where the boundary migration rates required to maintain a constant grain size are orders of magnitude higher than can be satisfactorily explained by diffusion-controlled migration. Alternative mechanisms have been proposed for rapid deformation-induced grain growth, including stress-driven boundary migration and breakaway from solute pinning $[11,20]$.

Similar to the subgrain size [21], the minimum grain size achievable in SPD is generally found to be related to the temperature-compensated strain rate during processing, given by the Zener-Holloman parameter $(Z)[11,22]$. It is therefore possible to achieve a smaller minimum grain size by lowering the deformation temperature, which results in the suppression of thermally activated restoration processes [23-25]. Indeed, the application of cryogenic deformation has been widely claimed to lead to the formation of nanocrystalline structures in $\mathrm{Al}[25], \mathrm{Cu}[23,24]$ and other alloys [26,27], offering the practical prospect of producing bulk nanograined materials by SPD. Typically, this involves heavily rolling materials at liquid nitrogen temperatures, which have already been deformed by a severe deformation technique such as ECAE $[23,24,28]$. It has also been claimed that nanograin structures can be produced by direct cryogenic rolling [29]. However, most of the above work has focused on copper samples where twinning is an additional source of grain subdivision $[23,24,28]$.

Because of the fine-scale of the crystallite sizes produced in cryogenic SPD processing routes, much of the information presented in the literature is based on transmission electron microscopy (TEM) evidence (e.g. $[1,5,7,23,29])$. As a result, reliable statistical data, with sufficient resolution, has frequently not been obtained that fully characterizes the misorientations of boundaries within the materials over a representative assembly of grains. It is thus often unclear whether the microstructures produced by cryogenic SPD routes are true nanograin structures, in that they have a HAB spacing in all dimensions of less than $100 \mathrm{~nm}$ (where a HAB is conventionally taken to have a misorientation greater than $15^{\circ}$ ), or still contain a large fraction of low-angle boundaries (LABs). In addition, deformation structures produced by plane strain compression are typically highly elongated [13] and unlikely to have nanoscale $\mathrm{HAB}$ spacings in all dimensions.

The main aim of the research presented here was to investigate the effect of changing the deformation mode and lowering the temperature on the rate of grain refinement and the limiting grain size achievable by an SPD process. The factors that control the minimum grain size that can be obtained in an SPD process will also be discussed. This was achieved by studying the deformation structure evolution in a dilute aluminium alloy, cryogenically deformed under plane strain conditions, at a range of temperatures, following pre-processing by ECAE to give an initial starting submicron grain structure. The results are thus in line with the processing route adopted by several other studies in the literature $[23,24,28]$. Material characterization was carried out by electron backscatter diffraction (EBSD) orientation mapping in a scanning electron microscope (SEM). This technique is difficult to implement with nanoscale structures and such an approach has only recently become possible due to advances in the resolutions achievable with field emission SEMs (FEGSEM) operated under optimized conditions [30,31]. Orientation mapping has the considerable advantage over TEM-based techniques of being able to provide statistically reliably data from large numbers of boundaries and representative sample areas.

\section{Experimental}

A model high-purity $\mathrm{Al}-0.13 \mathrm{wt} . \% \mathrm{Mg}$ alloy was used for this investigation, selected to contain no second-phase particles, but with a sufficient solute level to inhibit rapid boundary migration. The same material has previously been used for several other deformation studies (e.g. $[3,4,11,12,19])$. The alloy was DC cast from 99.999 wt. $\%$ purity feedstock, cold rolled $50 \%$ and recrystallized, giving a starting grain size of $\sim 300 \mu \mathrm{m}$. Square cross-section billets $\left(100 \mathrm{~mm} \times 15 \mathrm{~mm}^{2}\right)$ were machined in the rolling direction and pre-processed by ECAE, via route A, through a $120^{\circ}$ die at $298 \mathrm{~K}$ to a total effective strain of $\sim 10$ $\left(\dot{\epsilon} \sim 0.3 \mathrm{~s}^{-1}\right)$ using 15 passes. Plane strain compression (PSC) specimens $12 \times 8 \times 10 \mathrm{~mm}$ were cut from the ECAE billets and deformed in a channel die to a true strain of $\varepsilon_{\mathrm{tr}}=2.8,\left(\dot{\epsilon}=10^{-2} \mathrm{~s}^{-1}\right)$. Channel die PSC was chosen to simulate rolling under more controllable conditions of constant temperature and strain rate. The rig and samples were immersed in baths, chilled with liquid nitrogen, to temperatures from $298 \mathrm{~K}$ down to $77 \pm 2 \mathrm{~K}$. PTFE tape, at room temperature, and molybdenum disulphide/graphite lubricants, at cryogenic temperatures, were used to minimize friction. Following PSC at $77 \mathrm{~K}$, some samples were rolled at room temperature to an additional true strain of 2.8 (nominal strain rate of $10^{-1} \mathrm{~s}^{-1}$ ), as by this stage they were too thin to be deformed further in the channel die. The specimen orientation convention for flat rolling is used throughout, with ND parallel to the compression direction, $\mathrm{RD}$ the extension direction, and TD constrained by the die channel. During PSC the specimen orientations ND, TD and RD were aligned parallel to ND, TD and ED, respectively, relative to the ECAE die exit channel. ND and RD were thus aligned with the directions of minimum grain width and maximum grain elongation in the ECAE-processed starting material $[3,4,12]$. 
The deformed samples were sectioned through their centre parallel to the ND-RD/ED plane, before metallographic preparation and electropolishing. Their microstructures were characterized by high-resolution EBS imaging and EBSD orientation mapping in an FEI Siron FEGSEM, fitted with an HKL-EBSD system. The spatial and angular resolution of the EBSD system was $\sim 10 \mathrm{~nm}$ and $\sim 1^{\circ}$, respectively [30,31]. In the EBSD maps presented, HABs are shown by black lines and have misorientations $\geqslant 15^{\circ}$, while LABs are depicted by white lines and have misorientations $<15^{\circ}$. Due to misorientation noise, boundaries were cut-off of at less than $1^{\circ}$. Red, green and blue colour levels are proportional to the three Euler angles. Average linear intercept measurements of the $\mathrm{HAB}$ and LAB spacings were made in ND $\left(\lambda_{\mathrm{ND}}\right)$ and $\mathrm{RD} / \mathrm{ED}\left(\lambda_{\mathrm{RD}}\right)$, as well as the fraction of HAB area, and boundary misorientations. For each measurement, data from several maps was averaged over 2000 grains. $\lambda_{\mathrm{RD}}$ was measured by manual line scanning, as small deviations from alignment with the reference frame by thin ribbon grains lead to unrealistically low aspect ratios with the EBSD analysis software. Volume fractions of individual texture components were determined within an angular spread of $15^{\circ}$ from the ideal orientation.

As materials produced by SPD contain deformation structures with a mixture of HABs and LABs that evolve from a coarse-grained starting condition, it is not always clear what constitutes a "grain" after deformation to high strain levels. To clarify this issue, here, the term grain will be used to refer to a crystallite bordered by a continuous boundary perimeter of greater than $15^{\circ}$ in misorientation.

\section{Results}

\subsection{The starting material after ECAE processing}

Fig. 1a shows the typical submicron grain structure of the Al- $0.13 \mathrm{Mg}$ alloy in the starting condition for cryogenic channel die deformation, following ECAE processing by route $\mathrm{A}$ to an effective strain of 10 at room temperature. An average transverse $\mathrm{HAB}$ spacing in ND of $\sim 0.55 \mu \mathrm{m}$ and grain aspect ratio of $\sim 2.3$ were measured from the EBSD maps. The fraction of HAB area was $75 \%$. The grain refinement mechanisms involved during ECAE processing of the same material have been previously discussed (e.g. $[3,4,12,32,33])$. At this strain level ECAE processing leads to the development of a fibrous deformation structure aligned close to ED, containing a mixture of elongated thin ribbon grains and lower aspect ratio submicron grains $[12,32,33]$. This microstructure evolves from a lamellar boundary structure formed at lower strains, which contains a higher fraction of low-angle lamellar and transverse boundaries. By a strain of 10 , the average grain width has converged with the subgrain size and already approached a minimum steady-state spacing [12]. However, there are still a significant proportion $(\sim 25 \%)$ of retained LABs within many of the larger elongated grains, predominantly aligned in the transverse direction $[12,32,33]$

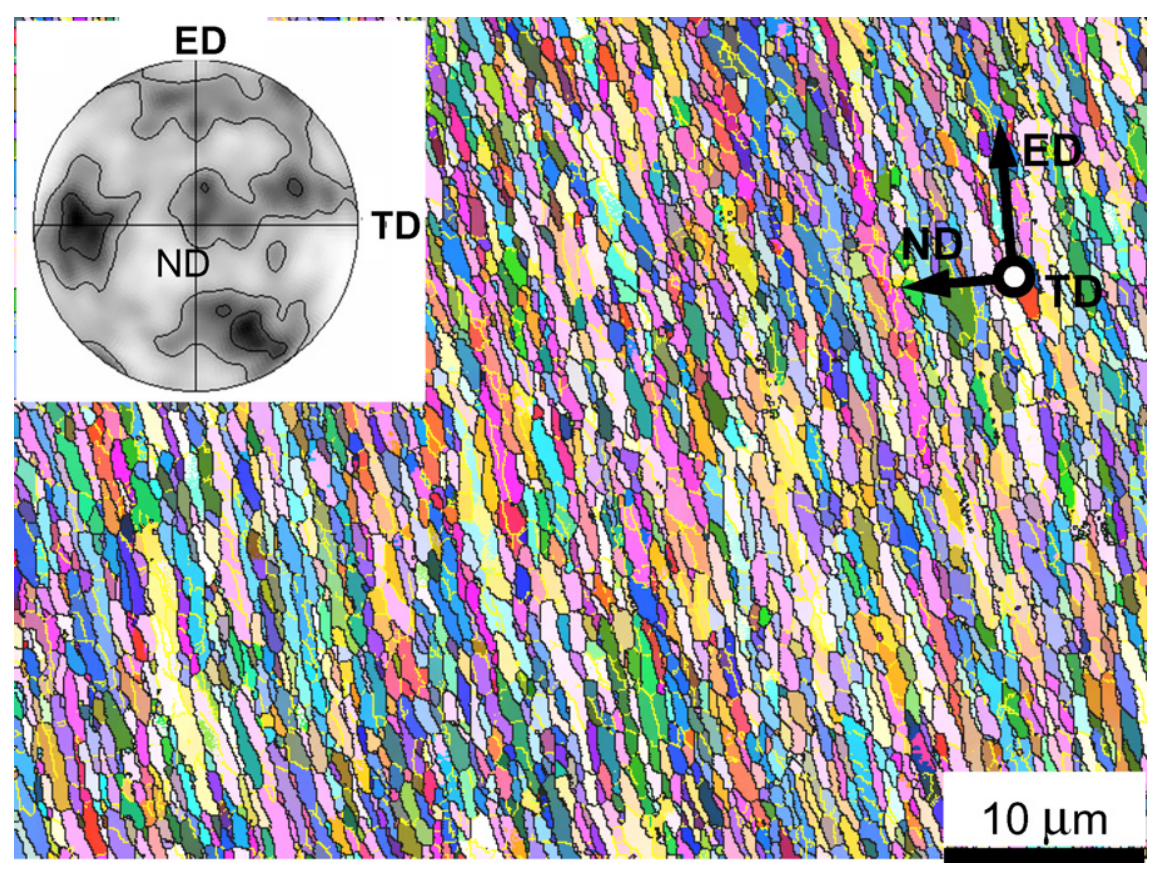

Fig. 1. EBSD map depicting the ultrafine grain structure of the Al- $0.13 \mathrm{Mg}$ alloy after ECAE processing to an effective strain of 10 , which was the starting condition for the plane strain compression testing. The initial texture is shown in the 111 pole figure inset. 
3.2. Grain refinement during cryogenic plane strain compression

The deformation structures obtained by PSC were strongly temperature dependent. In Fig. 2 electron backscattered images and EBSD maps are depicted from samples deformed by PSC to a true strain of 2.1 at decreasing temperatures. The deformation structure evolution at $77 \mathrm{~K}$ to a strain of $\varepsilon_{\text {true }}=2.8 \mathrm{can}$ also be seen in Fig. 3. Average boundary spacings and other statistical data obtained from the EBSD maps is given in Figs. 4 and 5. It should be noted that it is difficult to obtain EBSD data from such fine-scale structures. However, the level of indexing achieved was of the order of that theoretically
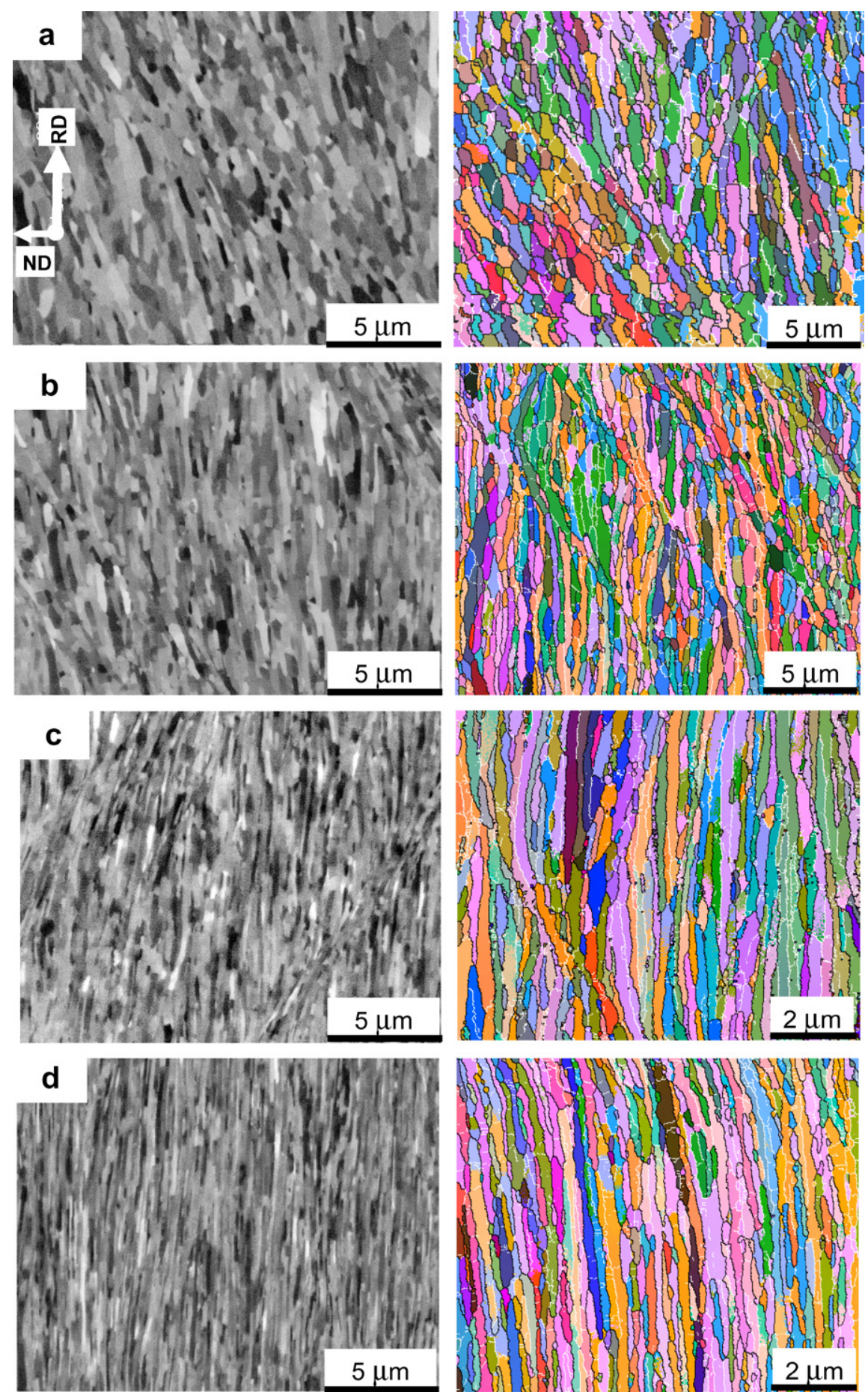

Fig. 2. Example backscattered electron images and EBSD maps from the submicron-grained $\mathrm{Al}-0.13 \mathrm{Mg}$ alloy deformed by plane strain compression to a true strain of 2.1 at (a) $298 \mathrm{~K}$, (b) $213 \mathrm{~K}$, (c) $143 \mathrm{~K}$ and (d) $77 \mathrm{~K}$. Note the different magnifications used in the EBSD maps and the exceptionally fine-scale in (c) and (d). 

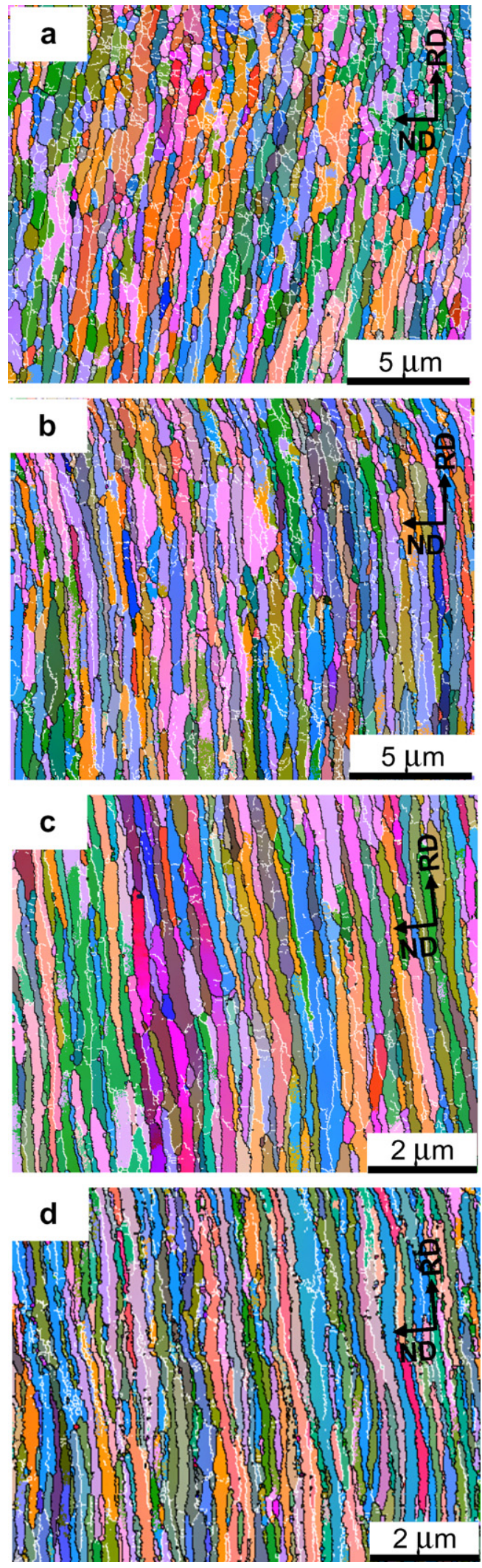

Fig. 3. EBSD maps showing the deformation structure evolution during plane strain compression at $77 \mathrm{~K}$; at true strains of (a) 0.5 , (b) 0.7 , (c) 1.1 and (d) 2.8. Note the different magnifications.

expected for a material containing such a high density of boundaries [31], and good agreement between the back-
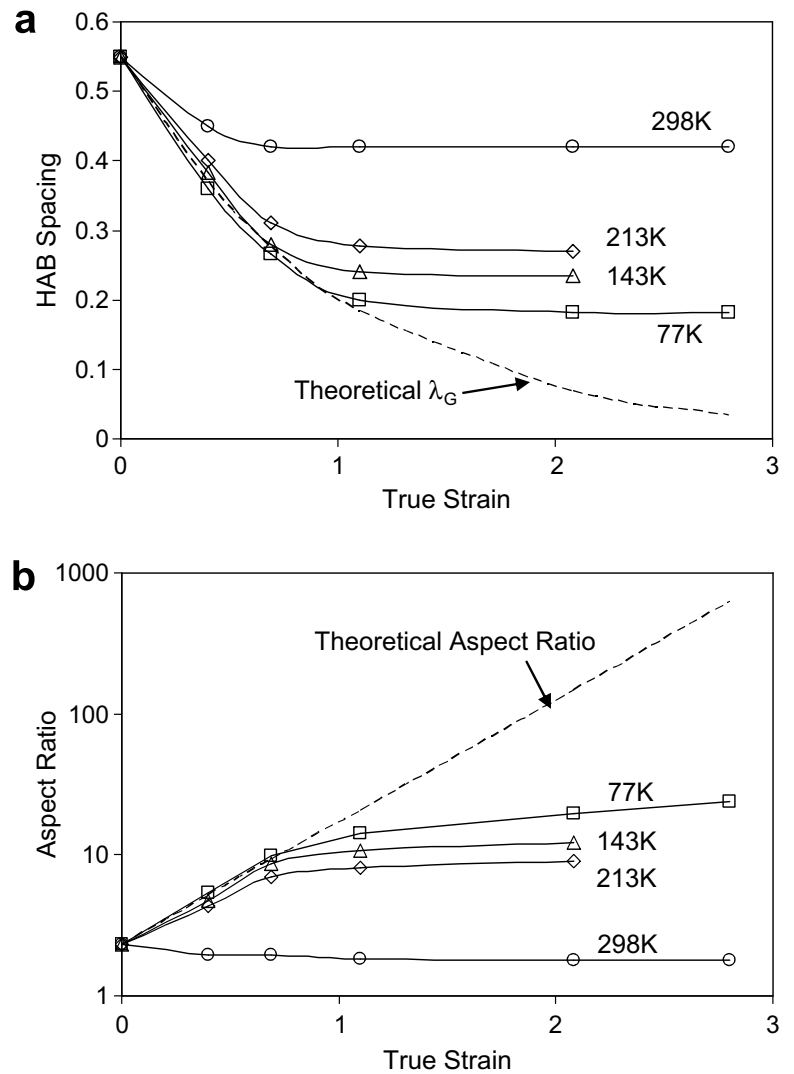

Fig. 4. Average statistical data obtained from EBSD maps of the PSC samples, showing (a) the transverse HAB spacing in ND $\left(\lambda_{\mathrm{ND}}\right)$ and (b) the grain aspect ratio as a function of strain at different temperatures. Theoretically predicted curves calculated from the geometrically required shape change of a grain with strain are also shown for comparison (dashed lines).

scattered images and processed EBSD maps gave a high level of confidence in the EBSD data.

At temperatures down to $143 \mathrm{~K}$ the deformation structures were disrupted by the appearance of shear bands, sometimes referred to as "S" bands [34] (Fig. 2a-c). The shear bands cut through the elongated grain structures and can thus be considered to be transgranular. At room temperature the shear bands were $\sim 5 \mu \mathrm{m}$ wide and contained submicron grains realigned and elongated in the direction of shear. The shear bands reduced in width and intensity with decreasing temperature, until they completely vanished at $77 \mathrm{~K}$ (Fig. 2d). The shear bands formed near the onset of plane strain compression, and were originally aligned at an angle of $35-40^{\circ}$ to $\mathrm{RD}$, before rotating towards RD with continued deformation. As shear banding occurred at low strains and was more localized and weaker below room temperature, this mainly resulted in increased heterogeneity within the material, in terms of local grain alignment, but did not greatly affect the underlying boundary parameters at lower temperatures. However, at room temperature shear banding made it more difficult to obtain reliable measurements of grain size and aspect ratio via the linear intercept method due, to the misalignment of significant 

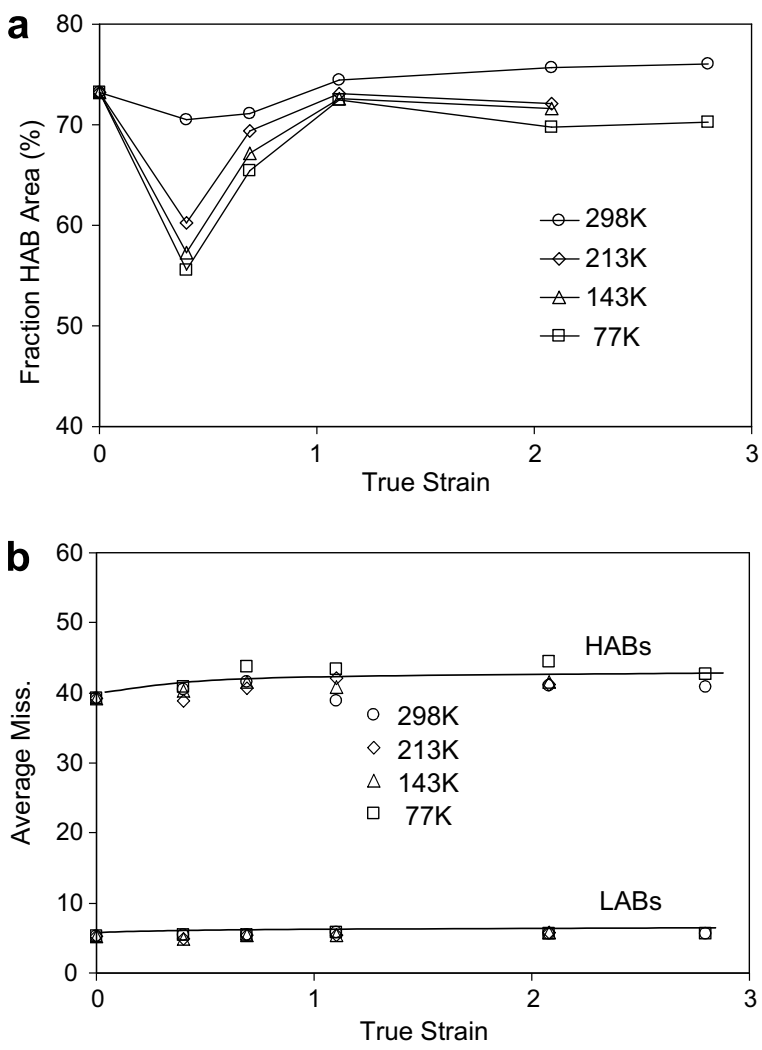

Fig. 5. The fraction of HAB area (a) and the average misorientation of low-angle $\left(1-15^{\circ}\right)$ and high-angle $\left(15-62.5^{\circ}\right)$ boundaries (b) as a function of strain on PSC deformation at different temperatures.

volumes of the material with respect to the RD-ND reference frame.

In the plane strain compression samples the starting deformation structure inherited from the pre-ECAE-processed, submicron-grained starting material was aligned with the direction of grain elongation approximately parallel to RD and the compression direction, ND, parallel to the direction of initial minimum grain width. Plane strain compression thus resulted in a natural tendency to further reduce the grain width in ND and for the grain boundaries to become extended parallel to RD. If a material deforms homogeneously the grain shape is directly coupled to the strain tensor [17] and in PSC the transverse HAB spacing will be geometrically required to reduce in proportion to the sample reduction ratio, which can be related to the initial grain width, $\lambda_{0}$, and true strain, $\varepsilon_{\text {true }}$, by [19]

$\lambda_{\mathrm{G}}=\lambda_{0} \exp \left(-\epsilon_{\text {true }}\right)$.

Curves corresponding to the theoretical geometric reduction in HAB spacing, $\lambda_{\mathrm{G}}$, given by Eq. (1), and the similarly predicted increase in grain aspect ratio, relative to that of the ECAE processed starting material, are plotted in Fig. $4 \mathrm{a}$ and $\mathrm{b}$, along with the corresponding measured data.

On room temperature channel die compression, following severe deformation by ECAE, only a small reduction in grain size was observed (Fig. 2a). In Fig. 4a the theoretical curve, $\lambda_{\mathrm{G}}$, can be seen to decrease more rapidly than the measured HAB spacing in ND from the outset of deformation and to continue to reduce with increasing strain, while the actual rate of reduction in $\lambda_{\mathrm{ND}}$ quickly falls off and approaches a new pseudo-steady grain width at a strain of $\varepsilon_{\text {true }}>0.7$. This resulted in only a limited reduction in $\lambda_{\mathrm{ND}}$, from 0.55 to $0.42 \mu \mathrm{m}$, with little change in grain aspect ratio (Fig. 4b). Equally, the HAB fraction went on to only increase slightly above that seen in the initial ECAE-processed material and there was a very modest increase in the average HAB misorientation (Fig. 5). Without a simultaneous increase in $Z$, a change in deformation mode from ECAE to PSC, therefore, merely gave rise to a small readjustment of the deformation structure and the rapid attainment of a new steady-state minimum $\mathrm{HAB}$ spacing.

During cryogenic PSC deformation the starting submicron grain structure became compressed and rapidly developed into a high aspect ratio lamellar $\mathrm{HAB}$ structure (Fig. 3), while at higher strains the rate of reduction in HAB boundary spacing slowed dramatically and again approached a new pseudo-steady-state spacing in ND (Fig. 4a). With reducing temperature (Fig. 2), the initial ultrafine-grained structure became more elongated parallel to $\mathrm{RD}$, and at $77 \mathrm{~K}$ a very fine lamellar grain structure was formed with a transverse $\mathrm{HAB}$ spacing approaching the nanoscale $(100 \mathrm{~nm})$. The grain aspect ratio also greatly increased with decreasing temperature, from $\sim 2.3$ at $298 \mathrm{~K}$ to 15 at $77 \mathrm{~K}$. Furthermore, the boundaries within the lamellar structure were more planar than seen in the samples deformed at room temperature. In contrast to the behaviour seen at room temperature, as the deformation temperature was lowered, the transverse boundary spacing $\left(\lambda_{\mathrm{ND}}\right)$ and grain aspect ratio $\left(\lambda_{\mathrm{RD}} / \lambda_{\mathrm{ND}}\right)$ initially closely followed their respective theoretical curves before departing to approach a new finer pseudo-steady-state grain width at higher strains. However, deviation from the predicted $\lambda_{\mathrm{G}}$ spacing and grain aspect ratio occurred more slowly the colder the deformation temperature and the strain required to approach a constant $\lambda_{\mathrm{ND}}$ increased, from $\sim 0.7$ at room temperature to $\sim 1.2$ at $77 \mathrm{~K}$.

From Fig. 5a it can be observed that on changing the deformation mode to PSC there is a small early decrease in $\mathrm{HAB}$ area fraction at room temperature, which is exaggerated as the temperature is reduced. This effect results from the introduction of new LABs within the starting submicron grains, on changing the deformation mode, as the equilibrium cell size decreases with temperature. For example, in Fig. 3a, at low strains in the PSC sample deformed at $77 \mathrm{~K}$, many more new LABs can be observed within the original grains. The HAB fraction then increased with further strain, at all the temperatures, approaching a similar level close to that of the starting material by a strain of $\varepsilon_{\text {true }} \sim 1.1$. With further deformation, while the HAB fraction continued to increase slightly at room temperature, a small decrease was seen at cryogenic temperatures. However, during PSC it was difficult to distinguish any evidence for new HABs being formed from orientation splitting 
within the pre-existing grains inherited from the ECAEprocessed starting material. The average misorientations of HABs $\left(15^{\circ}-60^{\circ}\right)$ all behaved similarly irrespective of temperature (Fig. 5b) and increased marginally on plane strain compression, while the average LAB misorientations remained relatively constant.

Fig. 3d shows the extremely elongated ribbon grain microstructure obtained at the maximum strain that could be achieved by cryogenic plane strain compression, of $\varepsilon_{\text {true }}=2.8$, at $77 \mathrm{~K}$. The average transverse boundary spacing (including both LABs and HABs) was $130 \mathrm{~nm}$. However, the minimum transverse $\mathrm{HAB}$ spacing $\left(\geqslant 15^{\circ}\right.$ misorientation) was $\sim 180 \mathrm{~nm}$. In comparison, the average $\mathrm{HAB}$ spacing in $\mathrm{RD}$, or grain length, at this temperature was considerably larger and was estimated to be $\sim 3.0 \mu \mathrm{m}$, which is greater than that seen in the ECAE-processed starting material, with some ribbon grains extending for up to $10 \mu \mathrm{m}$.

\subsection{Grain structure stability}

To test the stability of the cryogenic deformation structures, subsequent to plane strain deformation in liquid nitrogen, samples were either held for a prolonged period of time at room temperature, or immediately further deformed by rolling, as by this stage they were too thin for additional deformation to be possible in the channel die. The results of these experiments are depicted in Fig. 6. From Fig. 6a it can be seen that samples stored for up to 6 months at room temperature, with no further deformation, showed only a very slight increase in the average spacing of their lamellar HAB structure, by $\sim 0.02 \mu \mathrm{m}$. In comparison, when the same specimens previously deformed by plane strain compression at $77 \mathrm{~K}$ were subsequently rolled at room temperature, $\lambda_{\mathrm{ND}}$ rapidly increased by a factor of three until it reached a new plateau with a similar value of grain width to that of the samples deformed only by uninterrupted plane strain compression at room temperature. Furthermore, from comparing Fig. $6 \mathrm{~b}$ and Fig. 2a, it can be seen that on reverting to room temperature deformation, following channel die compression at $77 \mathrm{~K}$, the deformation structures became indistinguishable from those observed after continuous PSC deformation at room temperature. This suggests that the HAB spacings dynamically readjust towards a pseudosteady-state grain size, in response to a change in $z$, at a rate that is far higher than possible under static annealing conditions.

\subsection{Texture development during plane strain compression}

The relatively weak texture of the ECAE-processed starting material is shown in the 111 pole figure in Fig. 1. In the ECAE die exit channel frame (adopted here to be compatible with the PSC sample reference system) the texture can be described as having $\{001\}<110>$ and $\{1112\}<110>$ components with no peak intensities greater

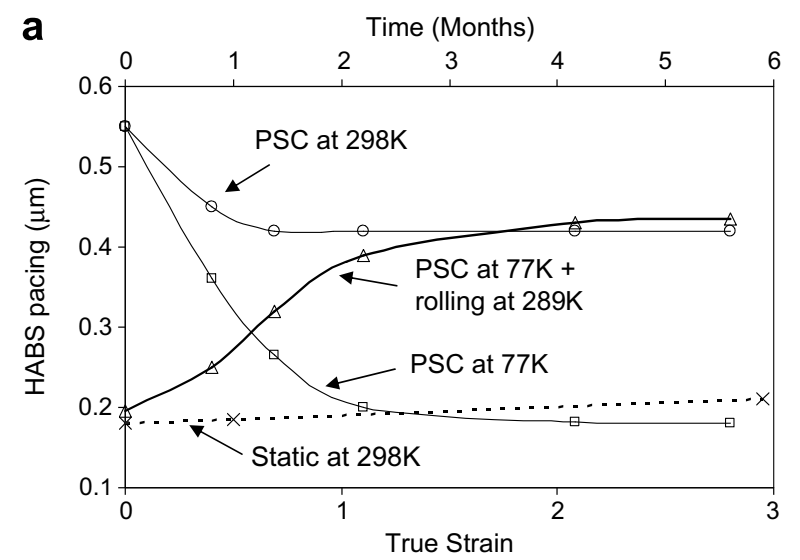

b

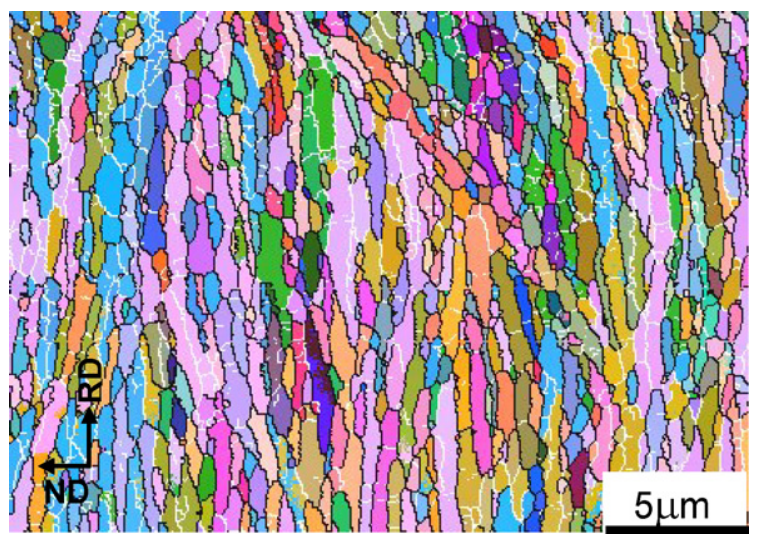

Fig. 6. (a) The transverse HAB boundary spacing, $\lambda_{\mathrm{ND}}$, plotted against storage static time and strain during deformation by rolling, both at room temperature, following PSC at $77 \mathrm{~K}$, compared to uninterrupted PSC deformation at 298 and $77 \mathrm{~K}$, and (b) an EBSD map from a sample rolled at room temperature to a true strain of 2.8 following PSC in liquid nitrogen.

than three times random. In Fig. 7 examples of 111 pole figures are given, following PSC deformation at different temperatures at $\varepsilon_{\text {true }}=2.1$ and strains at $77 \mathrm{~K}$. The effect of temperature and strain on the development of the main rolling texture components can be seen in Fig. 8. During PSC deformation, a typical face-centred cubic rolling texture formed in all the samples, the main components being brass $\{110\}<112>$, copper $\{112\}<111>$ and $\mathrm{S}$ $\{123\}<634>$. The overall texture intensity increased with increasing strain and decreasing temperature, although individual texture components exhibited different trends in their development. The strongest texture, with peaks of $\sim 10$ time random, was seen in the PSC sample deformed at $77 \mathrm{~K}$ to the maximum strain employed of $\varepsilon_{\text {true }}=2.8$.

Three stages of texture development can be seen on deformation at $77 \mathrm{~K}$ (Fig. 10b). At low strains, the three main rolling texture components all evolved rapidly from the starting weak ECAE texture, with a simultaneous reduction in strength of the original ND-rotated cube $\{001\}<110>$ and $\{112\}<110>$ components. Initially, the $\mathrm{S}$ and copper components increased at a higher rate and a small fraction of Goss $\{110\}<100>$ formed early 

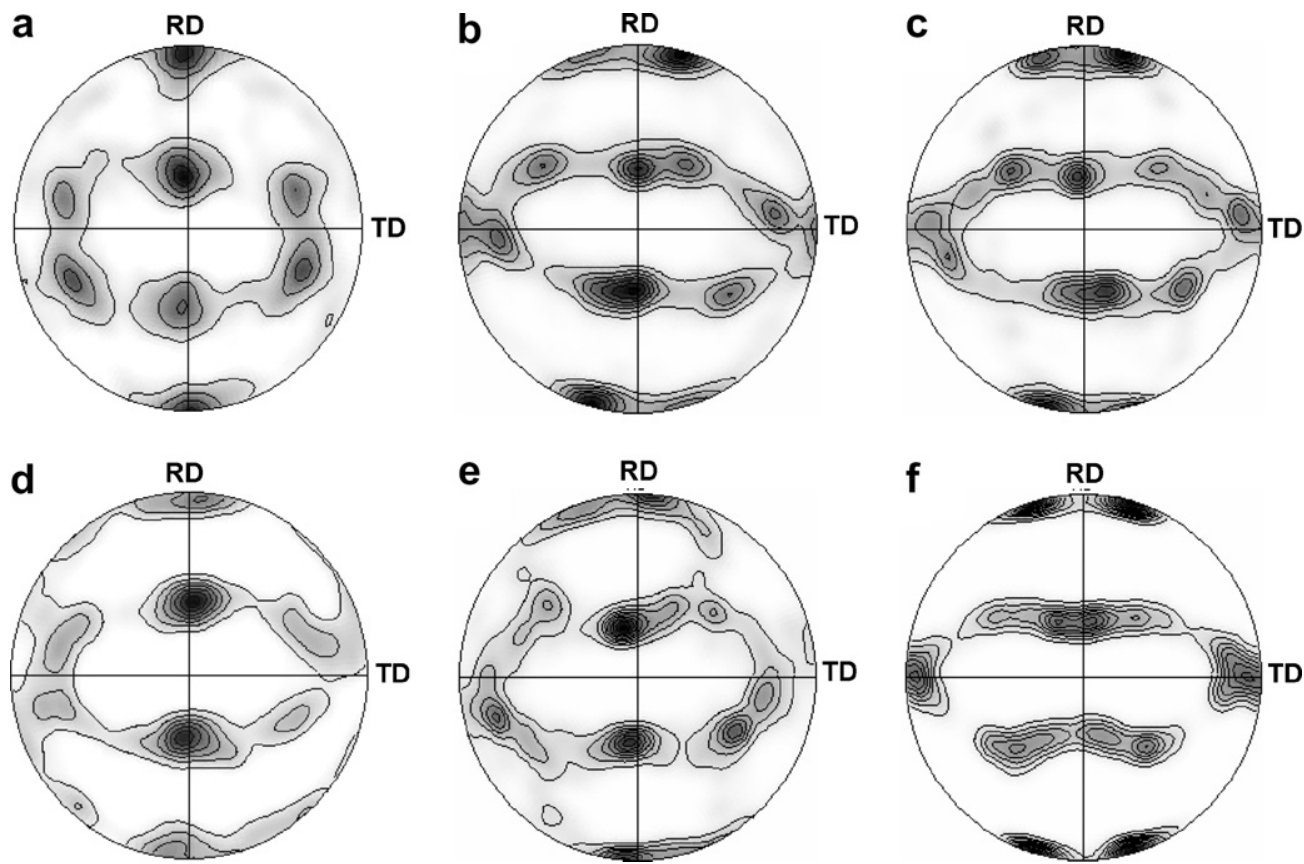

Fig. 7. 111 Pole figures showing the textures present after PSC deformation to a strain of $\varepsilon_{\text {true }}=2.1$ at (a) room temperature, (b) $213 \mathrm{~K}$, (c) $143 \mathrm{~K}$, and at $77 \mathrm{~K}$ on deformation to a strain of (d) $\varepsilon_{\text {true }}=0.5$, (e) $\varepsilon_{\text {true }}=1.1$ and (f) $\varepsilon_{\text {true }}=2.8$.
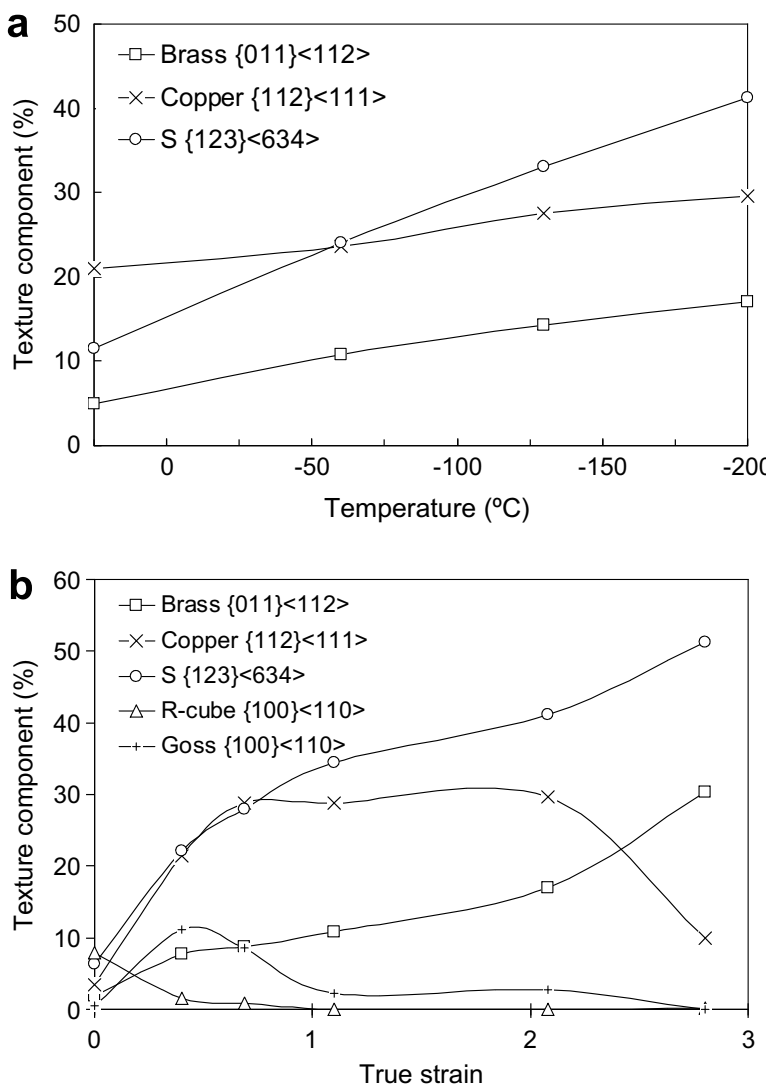

Fig. 8. The development of rolling texture components (within $15^{\circ}$ of the ideal orientations), during PSC as a function of (a) temperature at a strain of $\varepsilon_{\text {true }}=2.1$ and (b) strain at $77 \mathrm{~K}$. on, but then died off quickly. In the strain range from 1.1 to 2.1, the brass and $\mathrm{S}$ components moderately strengthened, while the copper component remained almost constant in intensity. Finally, upon further deformation to $\varepsilon_{\text {true }}=2.8$, the volume fractions of $\mathrm{S}$ and brass increased further at the expense of copper. This feature of the texture development may also been seen from the 111 pole figures in Fig. $7 \mathrm{~d}-\mathrm{f}$, where the highest orientation intensity switches gradually from the poles on the ND-RD great circle ( $\mathrm{S}+$ copper $)$ to the poles on TD-RD great circle ( $\mathrm{S}+$ brass $)$.

\section{Discussion}

Here, we will first consider whether a change in deformation mode can be exploited to reinvigorate the rate of refinement in SPD by, for example, altering the dominant slip systems and disturbing the texture. This will be followed by a discussion of the potential for achieving a "true" nanograin structure by cryogenic deformation and the physical processes that control the limiting grain size obtainable.

\subsection{The effect of changing deformation mode}

All metal working process can be described by combinations of simple shear and pure shear modes [35,36]. As ECAE is a process in which simple shear dominates, and in plane strain plastic flow occurs in pure shear, plane strain compression of an ECAE-processed material provides the maximum possible change of deformation mode. With plane strain compression, following simple 
shear in ECAE using a $120^{\circ}$ die, the ideal principal shear plane also rotates from $60^{\circ}$ to $\pm 45^{\circ}$ relative to the $\mathrm{ED} /$ RD axis. Furthermore, changing deformation mode, to plane strain compression after a large shear deformation, will lead to a jump in the rate of geometric boundary compression, as the geometric reduction in grain width slows to a low rate at high strains in shear [17]. In addition, plane strain compression will give rise to the development of stronger deformation textures [37] (see below).

Despite the increase in rate of geometrically required grain compression that occurs on changing from ECAE to plane strain compression, the present experimental results show (Figs. 3-5) that without simultaneously reducing the temperature, altering the deformation mode had only a slight impact on the level of grain refinement. For example, at room temperature the minimum steady-state transverse $\mathrm{HAB}$ spacing only reduced from $\sim 0.55$ to $\sim 0.4 \mu \mathrm{m}$. Furthermore, there was a negligible change in any of the other average boundary parameters, such as the average boundary misorientations (Figs. 4 and 5), over and above that expected for continued ECAE deformation [12]. It can thus be concluded that a change in deformation mode alone leads only to a slight transient effect on reinvigorating grain refinement, before a new steady-state is established after only a relatively small additional strain. However, it can have the undesirable side effect of causing a reduction in the global uniformity of the grain structure from the promotion of shear banding.

\subsection{The effect of texture development}

On cryogenic plane strain compression a conventional rolling texture developed from the weak simple shearrelated texture seen after ECAE processing (Figs. 7 and 8). Rolling textures in aluminium alloys typically consist of a spread along the $\beta$ fibre between the copper, $\mathrm{S}$ and brass components. Generally, it is found that lowering the stacking fault energy and temperature favours the brass component at the expense of $\mathrm{Cu}$ and $\mathrm{S}$ [37]. In the dilute alloy studied, the $\mathrm{Cu}$ component was seen to be stronger at room temperature and reduce in favour of the brass orientation at cryogenic temperatures (Fig 9a). The strongest texture observed in the channel die samples was found after deformation at $77 \mathrm{~K}$, but with peaks of $\sim 10$ times random this was still not excessive relative to that found in heavily rolled, commercial-purity aluminium [38]. The overall texture development was thus broadly in agreement with the texture evolution seen during plane strain compression of aluminium alloys with conventional grain sizes [38]. However, the texture will be weakened by the shear banding seen at higher temperatures.

The development of a strong texture can narrow the orientation spread during deformation [39]. In some cases neighbouring grains may rotate towards the same end orientations, particularly if they already exist in texturerelated bands in the original structure [40]. This could potentially result in a reduced rate of increase in HAB area

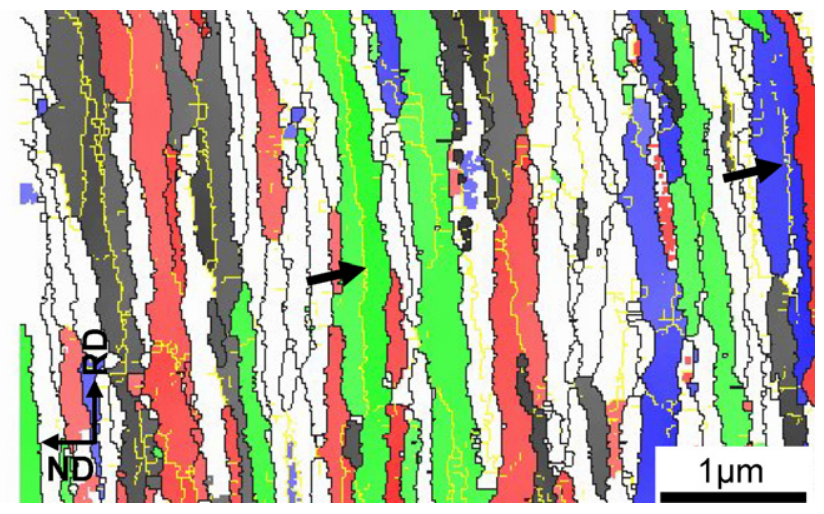

Fig. 9. An EBSD map showing grains with different variants of $\mathrm{S}$ texture in a sample deformed at $77 \mathrm{~K}$ to a true strain of 2.8. HABs are in black and LABs in yellow. The arrowed boundaries denote lamellar LABs that may have reduced in misorientation during PSC from HABs by texture convergence.

with strain. Possible evidence for this effect can be seen in Fig. 9, which depicts an EBSD map from a sample deformed to a strain of 2.8 at $77 \mathrm{~K}$, where grains with four variants of the $S\{123\}<634>$ component are presented in different colours. Examples of lamellar boundaries with low misorientations can be identified in the map, labelled with arrows. These boundaries have most probably evolved from the elongated boundaries seen in the ECAE-processed starting material, of which the vast majority was originally high-angle in character. These LABs could, therefore, have possibly formed from lamellar HABs present in the starting material, as the grains separated by them rotated towards the same texture component during plane strain compression.

Examination of Figs. 5a and 8 suggest that the slightly lower HAB fraction seen at high strains with reduced deformation temperature may coincide with the development of the stronger texture found in the cryogenically deformed samples. However, in Fig. 10 comparison of

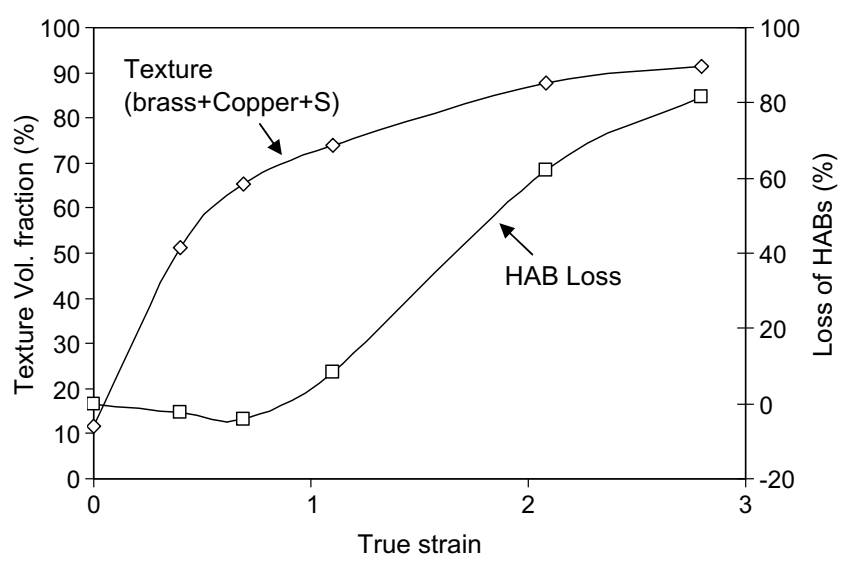

Fig. 10. The effect of strain on the development of the overall texture strength (brass + copper $+\mathrm{S}$ ) and the loss of lamellar HABs, calculated according to the difference between the measured and geometrically predicted $\mathrm{HAB}$ spacing at $77 \mathrm{~K}$. 
the effect of strain on the development of the overall rolling texture strength (brass + copper $+\mathrm{S}$ ) and the fraction of lost lamellar HABs, calculated according to the difference between the measured HAB spacing and the predicted geometrically required spacing from Eq. (1), shows little correlation to the stages of texture development. This suggests that the formation of a strong texture is only responsible for the loss of a small fraction of the HAB area developed during plane strain compression. For the development of a similar texture strength, Humphreys et al. has similarly estimated an upper bound loss of only $15 \%$ of the $\mathrm{HAB}$ area, based on a Taylor calculation of orientation changes from an initially randomly oriented grain assembly [19].

\subsection{Shear banding}

In the early stages of plane strain compression shear bands was seen to form at temperatures of $143 \mathrm{~K}$ and above, closely aligned to the plane of maximum shear stress in the channel die samples. With further deformation the shear bands subsequently underwent a rigid body rotation towards RD. This trend in shear band alignment is similar to that found in rolling [41]. Shear, or Lüders, bands have been widely reported during uniaxial testing of severely deformed submicron-grained alloys, and have negative consequences for ductility (e.g. [23,42]). During deformation of ultrafine-grained materials there is little dislocation storage within the grains, resulting in a near-zero work hardening rate $[23,42]$. Changing the deformation mode from shear to PSC, further results in the activation of latent slip systems, and a realignment of the shear plane with respect to deformation induced substructural boundaries. Both of these factors are known to promote shear instability during plastic deformation of metals [43]. Shear banding is also sometimes associated with a local rotation towards softer crystal orientations [41]. At lower deformation temperatures, new finer-scale subgrain boundaries were seen to form within the samples, indicating dislocation storage within the grains. This leads to an increase in the severely deformed starting material's strain hardening capacity and consequently it is not surprising that shear banding was seen to reduce in intensity at lower temperatures.

The concentration of strain within shear bands can act as a mechanism of grain refinement in severe deformation by inducing large local lattice rotations $[4,12]$. While at low strains shear bands have been shown to generate new $\mathrm{HABs}$ in coarse-grained starting materials during ECAE deformation $[4,12]$, here the shear bands were transgranular and their main effect was to reorientate the original fibrous grain structure in the ECAE-processed material, creating a more heterogeneous microstructure.

\subsection{Nanostructures by cryogenic severe deformation}

Other authors have used a similar processing route, of cryogenic rolling of copper following ECAE deformation to ultra-high strains, in combination with light annealing, to produce nanocrystalline materials with optimized bimodal grain structures [23,24]. However, they have not quantitatively analyzed the deformation structures formed. In the $\mathrm{Al}-0.1 \% \mathrm{Mg}$ alloy studied here, the results show that cryogenic plane strain deformation results in compression of the submicron $\mathrm{HAB}$ structure formed in the ECAE starting material, with little or no further grain subdivision taking place. This can be seen from Fig. 4 , where at low temperatures the grain width, $\lambda_{\mathrm{ND}}$, and the grain aspect ratio initially closely follow the theoretical predicted curves from Eq. (1), until they tail off to approach limiting values at high strains. Furthermore, little evidence of grain subdivision was found in the EBSD maps. Other work has also shown that no significant grain subdivision takes place on rolling fine-grained $(<10 \mu \mathrm{m})$ starting materials at ambient temperatures [19]. The reduction in HAB spacing and increase in HAB area that occurs on plane strain compression of a submicrongrained starting material is thus largely a geometric effect, caused by the compression and extension of pre-existing boundaries in proportion to the shape change of the sample, until a new liming grain size is achieved which is controlled by the rate of dynamic recovery (see below). This equally results in a large increase in grain aspect ratio.

At the highest strain achieved, of $\varepsilon_{\text {true }} \sim 2.8$, the final microstructure formed by PSC cryogenic deformation at $77 \mathrm{~K}$ was characterized by a lamellar HAB structure, comprised of thin ribbon grains containing at least $30 \%,{ }^{1}$ mainly transverse, LABs. This LAB fraction was slightly higher than that seen in materials produced by ECAE at room temperature. The minimum transverse HAB spacing obtained, $\lambda_{\mathrm{ND}}$, was measured to be $\sim 180 \mathrm{~nm}$, with an average HAB spacing in RD of around $\sim 3.0 \mu \mathrm{m}$. Such a microstructure cannot, thus, be described as being "truly" nanograined in the same sense as a randomly textured material produced by, for example, crystallization of a metallic glass. However, if the distinction between LABs and HABs is not considered, the $130 \mathrm{~nm}$ minimum crystallite size measured, which includes all boundaries greater than $1^{\circ}$ in misorientation, is verging on nanocrystalline. Because a steady transverse $\mathrm{HAB}$ boundary spacing was approached in the strain range studied, it will not be possible to reduce the grain size below this minimum value for $\lambda_{\mathrm{ND}}$ by deformation to higher strains, although this may lead to a slow fall in grain length, resulting in a lower aspect ratio grain structure, as has been seen in ECAE processing at room temperature [12].

\footnotetext{
${ }^{1}$ The orientation resolution of the EBSD technique is limited to $\sim 1^{\circ}$. Very low angle dislocation boundaries will therefore not be included in the statistics.
} 


\subsection{The minimum grain size in severe deformation}

A limiting transverse HAB spacing was reached at large strains, over the whole range of deformation temperatures studied, which will ultimately control the minimum grain size that can be achieved by a severe deformation process. This minimum boundary spacing is closely related to the equilibrium cell size at a given value of temperature-compensated strain rate and is reached shortly after the lamellar HAB spacing converges with the subgrain size $[11,12,22,32]$.

In monotonic deformation a material element must change shape, and if deformation is uniform the grain structure will compress at a similar rate. When thermally activated recovery processes are suppressed at cryogenic temperatures $\lambda_{\mathrm{ND}}$ was found to closely follow this geometric behaviour until $\varepsilon_{\text {true }}>1$ (Fig. 6). At higher strains the HAB spacing rapidly deviated from the geometrically predicted rate of compression and approached a new pseudo-steady-state minimum value. The minimum boundary spacing achievable is thus either controlled by equilibrium being established between the rate of compression of the $\mathrm{HAB}$ spacing and the rate of dynamic boundary migration, or alternatively, deformation must be accommodated by a mechanism that does not give rise to a uniform change in grain shape. Shear banding, involving the localization of shear, was observed in the plane strain compression samples, but only at low strains $(<1)$ and higher temperatures. At these strain rates grain boundary sliding is only a significant deformation mechanism above room temperature, or in materials with far smaller grain sizes [44], and it is difficult to conceive how it can make a contribution at such low deformation temperatures. Grain boundary sliding is also inconsistent with the lamellar HAB structures observed. Therefore, it is reasonable to assume a strain-coupled geometric requirement for grain structure compression at cryogenic temperatures.

Further evidence that an equilibrium is approached at high strains, between the rate of grain compression and dynamic grain boundary migration, can be demonstrated from the fact that when a sample compressed at $77 \mathrm{~K}$ was immediately deformed further at room temperature, the transverse $\mathrm{HAB}$ spacing readjusted back to that seen for the limiting ribbon grain width found on continuous PSC deformation at room temperature and the deformation structures became indistinguishable (Fig. 6). A similar dynamic behaviour is well known for subgrains during hot deformation, which readjust to form a new steady-state size following strain rate or temperature changes (e.g. [18]).

While the lamellar boundaries will increase in length in PSC, due to the extension of the sample parallel to RD, boundaries must also be lost to maintain a constant spacing in ND, possibly by competitive coarsening between ribbon grains. The fraction of lost boundaries, $f_{\text {lost }}$, required to maintain a constant $\lambda_{\mathrm{ND}}$ spacing, can be related to the strain $\left(\varepsilon_{\mathrm{tr}}\right)$ by $f_{\text {lost }}=1-\exp \left(-\epsilon_{\mathrm{tr}}\right)$.

In Fig. 4a the geometrically required transverse HAB spacing reached an equivalent steady-state value at 298 and $77 \mathrm{~K}$ at strains of $\varepsilon_{\mathrm{tr}} \sim 0.5$ and $\sim 1.1$, respectively. To maintain a constant transverse spacing would, therefore, require the loss of $\sim 90 \%$ and $\sim 80 \%$ of the lamellar HABs at these two corresponding temperatures.

The deformation structures following plane strain compression change in appearance with temperature, with higher aspect ratio, more planar lamellar boundary structures seen on cryogenic deformation. Vertex network and Monte Carlo models of similar lamellar structures have highlighted the effects of local boundary tension forces on the microstructure evolution during static annealing [45]. Simulations have shown that an ideal planar lamellar HAB structure, cross-linked by LABs, will initially coarsen by broad front $\mathrm{HAB}$ migration into neighbouring bands that contain dissimilar levels of average stored energy, in the form of transverse LABs with different densities and misorientations. There is also a simultaneous tendency for the boundaries to reach more equilibrium angles at cell nodes. This results in node switching and the necking-off, or spheroidization, of ribbon grain segments. However, considerable coarsening occurs in $\lambda_{\mathrm{ND}}$ before the aspect ratio approaches unity. In this context it is interesting that the structures seen at short and medium simulation times are very reminiscent of those observed after deformation in liquid nitrogen and at room temperature, respectively [45].

To maintain a steady-state transverse HAB spacing, $\lambda_{\mathrm{ND}}$, boundaries must migrate at a rate equal to that of their compression, $V_{\mathrm{C}}$, which can be related to the strain rate, $\dot{\epsilon}$, by

$V_{\mathrm{C}}=\frac{\mathrm{d} \lambda}{\mathrm{d} t}=\dot{\epsilon} \lambda_{\mathrm{ND}}$.

The boundary migration rate is usually assumed to be proportional to the driving force, $P$, and mobility, $M$

$V_{\mathrm{M}}=P \cdot M$.

Following the approach of Humphreys et al. [11], for conventional diffusion-controlled boundary migration, if the driving force is given by boundary curvature with $P \sim \gamma / 4 r$, the boundary migration rate, $V_{\mathrm{M}}$, will be

$V_{\mathrm{M}}=\frac{\gamma}{4 r} M_{0} \exp \left[\frac{-Q}{R T}\right]$,

where $r$ is the radius of curvature, $\gamma$ the HAB energy and $Q$ the activation energy for an atom to cross the boundary plane. For the same alloy used here, in static grain growth experiments in the temperature range $150-500{ }^{\circ} \mathrm{C}$, the preexponential factor $M_{0}$ has been determined to be $0.13 \mathrm{~m}^{4} \mathrm{~J}^{-1} \mathrm{~s}^{-1}$ and $Q=130 \mathrm{~kJ} \mathrm{~mol}^{-1}[11,46]$, while $\gamma$ has an accepted value of $\sim 0.32 \mathrm{~J} \mathrm{~m}^{-2}$ in aluminium [47]. Using these parameters, and taking $r$ as $\lambda_{\mathrm{ND}} / 2, \mathrm{HAB}$ velocities were calculated from Eq. (5) and are compared to the measured values determined from Eq. (3) in Table 1. As was 
Table 1

Estimated boundary migration velocities $\left(V_{\mathrm{C}}\right)$ required to maintain a steady-state transverse HAB spacing $\left(\lambda_{\mathrm{ND}}\right)$, compared to predicted static diffusion-controlled boundary migration rates $\left(V_{\mathrm{M}}\right)$ using a boundary curvature-estimated driving pressure $(P)$

\begin{tabular}{llllll}
\hline Temp $(\mathrm{K})$ & $\lambda_{\mathrm{ND}}(\mu \mathrm{m})$ & $P\left(\mathrm{~N} \mathrm{~m}^{-2}\right)$ & $V_{\mathrm{C}}\left(\mu \mathrm{m} \mathrm{s}^{-1}\right)$ & $V_{\mathrm{m}}\left(\mu \mathrm{m} \mathrm{s}^{-1}\right)$ & $V_{\mathrm{m}} / V_{\mathrm{C}}$ \\
\hline 298 & 0.42 & $3.8 \mathrm{E}+05$ & $4.2 \mathrm{E}-03$ & $7.6 \mathrm{E}-13$ & $2 \mathrm{E}-10$ \\
213 & 0.28 & $5.7 \mathrm{E}+05$ & $2.7 \mathrm{E}-03$ & $9.1 \mathrm{E}-22$ & $3 \mathrm{E}-19$ \\
143 & 0.24 & $6.7 \mathrm{E}+05$ & $2.3 \mathrm{E}-03$ & $2.6 \mathrm{E}-47$ & $1 \mathrm{E}-34$ \\
77 & 0.18 & $8.9 \mathrm{E}+05$ & $1.8 \mathrm{E}-03$ & $6.5 \mathrm{E}-78$ & $4 \mathrm{E}-75$ \\
\hline
\end{tabular}

first pointed out by Humphreys from research on materials deformed at room temperature and above, there is a massive difference between the estimated and predicated velocities [11]. From Table 1 it can be seen that the velocities predicted $\left(V_{M}\right)$ from Eq. (5) are lower than the experimentally calculated rates $\left(V_{\mathrm{C}}\right)$ by a factor of $10^{10}$ at room temperature and by progressively larger amounts at lower temperatures, being $\sim 10^{75}$ times slower at $77 \mathrm{~K}$. Similar anomalously high dynamic grain growth rates have been reported in nanocrystalline materials when deformed at room and liquid nitrogen temperatures $[48,49]$.

The mechanism controlling the abnormally high boundary migration rates that occur at low temperatures under dynamic conditions will limit the minimum grain size achievable by a severe deformation process. However, the physical mechanisms involved are currently unclear and can potentially vary with grain size, solute level and temperature. In Fig. 11 the estimated boundary migration rates, normalized with respect to the curvature-driven pressure $(\gamma / 4 r)$, are plotted against inverse temperature. Additional data is also included in this plot from the same starting material deformed under the identical conditions by PSC, from room temperature up to $200^{\circ} \mathrm{C}$. Two regimes can be seen with distinctly different slopes in

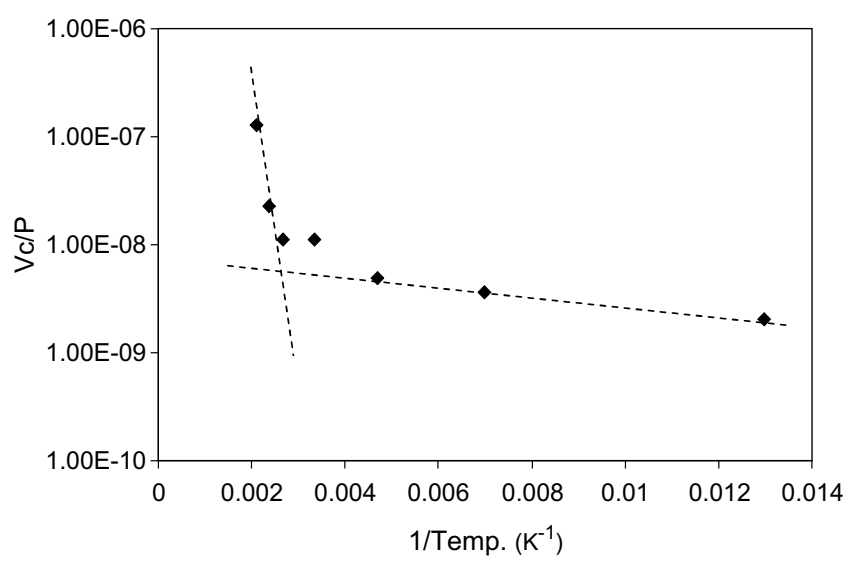

Fig. 11. Estimated lamellar HAB migration rates normalized with respect to surface tension-driven pressure $\left(V_{\mathrm{C}} / P\right)$ required to maintain a constant spacing during geometric compression in PSC, plotted against inverse temperature, and including data from 100 to $200{ }^{\circ} \mathrm{C}$ for the same alloy.
Fig. 11. Above room temperature, the steeper slope implies an activation energy of $\sim 60 \mathrm{~kJ} \mathrm{~mol}^{-1}$, whereas below $298 \mathrm{~K}$ the much shallower slope suggests an apparent "activation energy" as low as $\sim 1 \mathrm{~kJ} \mathrm{~mol}^{-1}$, which is physically unreasonable for a diffusional process. The activation energy above room temperature is, however, comparable to that expected for grain boundary diffusion in aluminium $\left(60-85 \mathrm{~kJ} \mathrm{~mol}^{-1}\right)$ [50].

Various explanations have been proposed for the anomalously high dynamic boundary migration rates observed at low temperatures. A higher driving force from internal stresses caused by elastic energy differences between neighbouring grains has been discounted in the literature, due to the low anisotropy of aluminium crystals. Estimates using variations in the Taylor factor between grains [11], or elastic anisotropy [20,51], result in a driving force between 5 and 30 times below that due to boundary tension. Equally, the low density of dislocations stored within ultrafinegrained materials during deformation do not provide a significant additional driving force for boundary migration [20]. In any event, no realistic increase in average driving force can account for the many orders of magnitude difference between the measured and estimated diffusion-controlled boundary migration rates seen at low temperatures. Mechanisms such as enhanced grain growth from coupling between grain boundary sliding [51] are also inapplicable with the current grain size and low deformation temperature.

It has been claimed that high transient vacancy concentrations can be generated during severe deformation [52], by climb of GB dislocations or the movement of screw dislocations jogs [53]. A modified form of Eq. (5) for vacancy diffusion-controlled boundary migration, which assumes atoms can only cross the boundary at vacant sites, is given by [54]

$V_{\mathrm{M}}=\frac{\gamma}{4 r} M_{0} C_{\mathrm{m}} \exp \left(\frac{-Q_{\mathrm{v}}^{\mathrm{m}}}{R T}\right)$,

where $c_{\mathrm{m}}$ is the momentary vacancy concentration in the boundary, and $Q_{\mathrm{v}}^{\mathrm{m}}$ is the energy for vacancy migration. If the transient vacancy concentration during deformation has a maximum value similar to that near the melting point $\left(C_{\mathrm{m}}=10^{-4}[53,55]\right)$, at room temperature the required activation energy to maintain a constant boundary spacing would be $\sim 60 \mathrm{~kJ} \mathrm{~mol}^{-1}$. This value is similar to that measured above $298 \mathrm{~K}$ and within the range of quoted values for vacancy migration in aluminium $\left(52-75 \mathrm{~kJ} \mathrm{~mol}^{-1}\right)$ [55], but does not explain the behaviour below room temperature.

A further possibility is that of stress-induced boundary migration. This mechanism, when associated with unpinning of boundaries by solute, is favoured by Gianola et al. [20] to explain the rapid grain growth seen during tensile deformation of nanocrystalline thin films at cryogenic temperatures. Molecular dynamics simulations and experimental measurements have shown that HABs can migrate under the action of an applied shear stress [50,56]. At very 
low stresses, Winning et al. [50,57] have found that for planar tilt boundaries the migration rate is proportional to the applied shear stress. In this work, boundary migration was found to be controlled by the climb of structural GB dislocation segments and the activation energy was measured to be $\sim 0.8 \mathrm{eV}\left(77 \mathrm{~kJ} \mathrm{~mol}^{-1}\right)$, which is close to the accepted value for grain boundary diffusion [50]. According to Winning et al. [57], for a $\sim 30^{\circ}$ tilt boundary the driving force is of the order of half the applied shear stress. Although it is doubtful if these measurements can be extrapolated beyond the yield stress, for the material investigated the maximum shear stresses estimated from the PSC tests were $\sim 120 \mathrm{MPa}$ at room temperature and $250 \mathrm{MPa}$ at $77 \mathrm{~K}$. Using Eq. (4), and the values of $M_{0}$ and $Q$ quoted by Winning et al. $[50,56]$, would, therefore, give stress-driven boundary velocities at these two temperatures of $\sim 10^{-5}$ and $\sim 10^{-44} \mu \mathrm{m} \mathrm{s}^{-1}$, respectively, which are far smaller than the measured values in Table 1.

As proposed by Humphreys et al. [11] and Gianola et al. [20], solute breakaway under dynamic conditions can result in significantly higher rates of boundary migration. During deformation, boundary spacings are continuously adjusting and boundaries may be forced away from their solute atmospheres. Furthermore, although the binding energy for a solute atom to a boundary will be greater at low temperatures [58], the diffusion rates will be very slow so that the solute atmospheres cannot readily re-form. However, the activation energy for boundary migration under breakaway conditions has been found experimentally to fall to a level similar to that for grain boundary diffusion, which has been measured to be around $60 \mathrm{~kJ} \mathrm{~mol}^{-1}$ in Al-Mg binary alloys [59]. This explanation is, therefore, again only applicable above room temperature.

An additional possibility is that grain boundary structures under dynamic conditions will be in a greater state of disorder, which could increase boundary mobilities. Molecular dynamics simulations have shown that grain boundaries can increase their disorder during plastic deformation $[60,61]$. As a result, under dynamic conditions grain boundaries will be in a non-equilibrium state, which will give rise to increased atomic shuffling and diffusion activity [61]. Since the boundaries are continuously trying to achieve a higher state of order, a simultaneous imbalance in pressure on the boundary may tend to bias structural relaxation and encourage accelerated boundary migration. However, this would still imply an activation energy related to grain boundary diffusion.

Therefore, either grain boundary diffusion, solute breakaway, or vacancy-assisted HAB migration could potentially account for the enhanced rate of boundary migration observed under dynamic conditions at room temperature to moderate elevated temperatures, but are many orders of magnitude too slow at cryogenic temperatures. Overall, none of the above reviewed mechanisms satisfactorily explains the abnormally large boundary migration rates needed to maintain a constant grain size at low deformation temperatures and suggests a conven- tional thermally activated boundary migration model is inappropriate under these conditions. Although it is beyond the scope of this paper to suggest a detailed mechanism, this would imply a collaborative process, or that there is breakdown in the law of proportionality between $V$ and $P$ (Eq. (4)) at very high driving pressures and low temperatures.

\section{Conclusions}

The grain structures formed in a submicron-grained aluminium alloy during plane strain compression at cryogenic temperatures have been studied by quantitative EBSD analysis, with the aim of gaining a better understanding of the factors that limit the formation of nanocrystalline grain sizes in SDP. Changing the deformation mode, from simple shear, in ECAE, to pure shear, in PSC, had little effect on grain refinement at room temperature, with only a minor readjustment of the boundary spacings. There was, however, an influence on the texture development and a reduction in the global uniformity of the grain structure due to the promotion of shear banding.

The increase in HAB area during plane strain compression of the submicron-grained starting material was geometrically related to the strain with little further grain subdivision. A large reduction in lamellar HAB spacing and increase in grain aspect ratio were seen with reducing temperature. However, a true nanocrystalline grain structure was not obtained. Deformation to an equivalent $98 \%$ rolling reduction at $77 \mathrm{~K}$ produced a microstructure comprised of thin ribbon grains, with a minimum $\mathrm{HAB}$ spacing of $180 \mathrm{~nm}$ and a grain length still well over a micron, while if all boundaries detected were considered, the minimum crystallite size obtained was $\sim 130 \mathrm{~nm}$.

It has been shown that at ultra-high plastic strains a pseudo-steady-state is approached where the rate of grain refinement stagnates. Although weakly influenced by texture and deformation mode, the steady-state HAB spacing is probably determined by a balance between the rate of geometric compression of the HAB structure, in response to the strain, and grain coarsening. The minimum grain size achievable by an SPD technique is, therefore, controlled by the rate of dynamic HAB migration. Estimates of the boundary velocities required to maintain an equilibrium spacing revealed that they are far higher than can be attributed to conventional surface tension-driven, diffusion-controlled boundary migration. At room temperature the activation energy is roughly comparable with migration rates that can be achieved by either grain boundary diffusion, solute breakaway, or if there was a high non-equilibrium concentration of vacancies present. In comparison, at cryogenic temperatures the minimum grain size achievable is limited by abnormally high boundary migration rates that are difficult to explain with existing theories of grain boundary mobility. 


\section{Acknowledgements}

The authors would like to acknowledge Professor F.J. Humphreys for some very helpful discussions and the financial support of the University of Manchester EPSRC Light Alloys Portfolio Partnership (EP/D029201/1) for this project.

\section{References}

[1] Valiev RZ, Islamgaliev RK, Alexandrov IV. Prog Mat Sci 2000;45:103.

[2] Humphreys FJ, Prangnell PB, Bowen JR, Gholinia A, Harris C. Phil Trans Roy Soc Lond A 1999;357:1663.

[3] Berta M, Apps PJ, Prangnell PB. Mat Sci Eng A 2005;410-411:381.

[4] Apps PJ, Berta M, Prangnell PB. Acta Mater 2005;53:499.

[5] Zhilyaev AP, Nurislamova GV, Kim B-K, Baró MD, Szpunar JA, Langdon TG. Acta Mater 2003;51:753.

[6] Wei Q, Zhang HT, Schuster BE, Ramesh KT, Valiev RZ, Kecskes LJ, et al. Acta Mater 2006;54:4079.

[7] Iwahashi Y, Furukawa M, Horita Z, Nemoto M, Langdon TG. Metall Trans 1998;29A:2245.

[8] Valiev RZ, Ivanisenko YuV, Rauch EF, Baudelet B. Acta Mater 1996;44:4705.

[9] Korznikov AV, Tram G, Dimitrov O, Korznikova GF, Idrisova SR, Pakiela Z. Acta Mater 2001;29:663.

[10] Hebesberger T, Stüwe HP, Vorhauer A, Wetscher F, Pippan R. Acta Mater 2005;53:393.

[11] Jazaeri H, Humphreys FJ, Bate SP. Mater Sci Forum 2006;519521:153.

[12] Prangnell PB, Huang Y, Berta M, Apps PJ. In: Prangnell PB, Bate PS, editors. Proceedings of the international symposium on fundamentals of deformation and annealing. Zurich: TransTech; 2007. p. 160.

[13] Liu Q, Huang X, Lloyd DJ, Hansen N. Acta Mater 2002;50:3789.

[14] Apps PJ, Bowen JR, Prangnell PB. Acta Mater 2003;51:2811.

[15] Börner I, Eckert J. Mater Sci Eng A 1997;226-228:541.

[16] Zebarjad SM, Sajjadi SA. Mater Design 2006;27:684.

[17] Bate PS, Hutchinson WB. Scripta Mater 2005;52:199.

[18] Duly D, Baxter GJ, Shercliff HR, Whiteman JA, Sellars CM, Ashby MF. Acta Mater 1996;44:2947.

[19] Jazaeri H, Humphreys FJ. Acta Mater 2004;52:3239.

[20] Gianola DS, Van Petegem S, Legros M, Brandstetter S, Van Swygenhoven H, Hemker KJ. Acta Mater 2006;54:2253.

[21] Castro-Fernandez FR, Sellars CM. Mater Sci Technol 1988;4:621.

[22] Mishra A, Kad BK, Gregori F, Meyers MA. Acta Mater 2007;55:13.

[23] Wang YM, Ma E. Acta Mater 2004;521:1699.

[24] Wang YM, Chen YM, Zhou F, Ma E. Nature Lett 2002;419:912.

[25] Lee YB, Shin DH, Park KT, Nam WJ. Scripta Mater 2004;51:355.

[26] Hayes RW, Rodriguez R, Lavernia EJ. Acta Mater 2001;49:4055.
[27] Wang TS, Peng JG, Gao YW, Zhang FC, Jing TF. Mater Sci Eng A 2005; $407: 84$

[28] Wang YM, Ma E, Chen MW. Appl Phys Lett 2002;80:2395.

[29] Nikhil Rangaraju T, Raghuram B, Vamsi Krishna K, Prasad Rao, Venugopal P. Mater Sci Eng 2005;398:246.

[30] Humphreys FJ. Mater Sci 2001;36:3833.

[31] Huang Y, Humphreys FJ. Mater Character 2001;47:235.

[32] Bowen JR, Prangnell PB, Humphreys FJ. Mat Sci Tech 2000;16:1246.

[33] Prangnell PB, Bowen JR, Apps PJ. Mater Sci Eng A 2004;375377:178.

[34] Hughes DA, Hansen N. Metall Trans A 1993;24:2021.

[35] Slater RAC. Engineering plasticity: theory and application to metal forming processes. London: Macmillan; 1977.

[36] Kocks UF, Tomé CN, Wenk H-R. Texture and anisotropy. Cambridge: Cambridge University Press; 2000.

[37] Leffers T. Scripta Metall 1968;2:447.

[38] Panchandeeswaran S, Filed DP. Acta Metall Mater 1995;43:1683.

[39] Bunge H. Texture analysis in material science. London: Butterworth; 1982.

[40] Heason CP, Prangnell PB. In: Zhu YT, Langdon TG, Valiev RZ, Semiatin SL, Shin DH, Lowe TC, editors. Proceedings of the ultrafine grained materials III. Warrendale, PA: TMS; 2004. p. 111.

[41] Hurley PJ, Humphreys FJ. Acta Mater 2003;51:1087.

[42] Hayes JS, Keyte R, Prangnell PB. Mat Sci Technol 2000;16:1259.

[43] Rauch EF. Solid State Phenom 1992;23-24:317.

[44] Kumar KS, Van Swygenhoven H, Suresh S. Acta Mater 2003;51:5743.

[45] Prangnell PB, Hayes JS, Bowen JR, Apps PJ, Bate PS. Acta Mater 2004;52:3193.

[46] Huang Y, Humphreys FJ. In: Gottstein G, Molodov DA, editors. Proceedings of the 1st international conference on recrystallization and grain growth. Berlin: Springer; 2001. p. 409.

[47] Murr LE. Interfacial phenomena in metals and alloys. Reading, MA: Addison-Wesley; 1975. p. 131.

[48] Jin M, Minor AM, Stach EA, Morris Jr JW. Acta Mater 2004;52:5381.

[49] Zhang K, Weertman JR, Eastman JA. Appl Phys Lett 2005;87:061921.

[50] Winning M, Gottstein G, Shvindlerman LS. Acta Mater 2001;49:211.

[51] Haslam AJ, Moldovan D, Yamakov V, Wolf D, Phillpot SR, Gleiter H. Acta Mater 2003;51:2097.

[52] Zehetbauer MJ, Steinter G, Schafler E, Korznikov A, Korznikova E. Mater Sci Forum 2006;503-504:57.

[53] Friedel J. Dislocations. New York: Pergamon Press; 1964.

[54] Ovid'ko IO, Rezos AB. Phys Solid State 2001;43:55.

[55] Balarin M. Phys State Solid A 1975;31:111.

[56] Suzuki A, Mishin Y. Mater Sci Forum 2005;502:157.

[57] Winning M, Gottstein G, Shvindlerman LS. Acta Mater 2002;50:353.

[58] Cahn JW. Acta Metall 1962;10:789.

[59] Frois C, Dimitriov O. Ann Chim Paris 1966;1:113.

[60] Fu H-H, Benson DJ, Meyers MA. Acta Mater 2001;49:2567.

[61] Hasnaoui A, Van Swygenhoven H, Derlet PM. Acta Mater 2002;50:3927. 